Gynäkol Geburtsh Rundsch 1994;34(Suppl 1):139

\title{
Ausriß von Kolposuspensionsfäden
}

nach Inkontinenz-perationen nach Raz und Burch infolge Sturztrauma

\begin{tabular}{|l|l|l}
\hline A.R. & Schurz \\
\hline
\end{tabular}

Gynäkol.-geburtsh. Abt. LKH Feldkirch (Vorst.: Prim. Dr. A. R. Schurz)

Prim. Dr. A. R. Schurz, Gynäkol.-geburtsh. Abt. Landeskrankenhaus Feldkirch, Carinagasse 47, A-6800 Feldkirch

4 Frauen nach vag. bzw. abd. Kolposuspension hatten ein auf-fallend ähnliches Schicksal

hinsichtlich ihrer Inkontinenz:

Nach Sturz sofortiges Rezidiv.

3 (davon 1 Ärztin) behaupten, noch im Hinfallen befürchtet zu haben, die Suspension könne gerissen sein, 1 davon hatte eine leichte vag. Blutung.

Alle 4 waren erheblich übergewichtig.

Anläßlich der Rezidivoperation konnte der beidseitige Ausriß der Schlingen an der

Perivesikalfaszie (Raz) bzw.

Vaginalfaszie (Burch) nachgewiesen werden. Nahtmaterial: Su-tron 0.

Diskussion

Durch eine bemerkenswerte Häufung von Zufällen konnte der Nachweis erbracht werden, daß die plötzliche Erhöhung des intraabd. Drucks bei schweren Stürzen zum Ausriß der Kolposuspensionsnähte und damit zum sofortigen Rezidiv führen kann.

Tabelle. 